\title{
Hábitos alimentares de crianças eutróficas e com sobrepeso em Viçosa, Minas Gerais, Brasil ${ }^{1}$
}

\author{
Food habits of well nourished and overweight \\ children in Viçosa, Minas Gerais state, Brazil
}

Silvia Eloiza PRIORE ${ }^{3}$

RE S U M O

\section{Objetivo}

Comparar os hábitos alimentares entre crianças eutróficas e com sobrepeso.

\section{Métodos}

Estudo caso-controle com 50 crianças eutróficas e 50 com sobrepeso, pareadas de acordo com o sexo, idade e condição socioeconômica, selecionadas a partir da avaliação nutricional de 2.074 crianças, entre 6 e 8 anos, de escolas públicas e privadas da área urbana de Viçosa, Minas Gerais. O estado nutricional foi classificado pelo Índice de Massa Corporal, segundo o Centers for Disease Control and Prevention. Um questionário de freqüência alimentar seletivo de alimentos que contribuem para o sobrepeso, bem como recordatórios alimentares habituais relativos aos dias de semana e finais de semana foram aplicados, sendo, nestes últimos, avaliada a ingestão de energia, carboidrato, lipídio, proteína, vitamina C, vitamina A, ferro, cálcio e fibras. Um quarto questionário foi aplicado, a fim de analisar a prática de realizar dietas pelas crianças.

\section{Resultados}

Destaca-se a excessiva ingestão de alimentos pelo grupo com sobrepeso, evidenciando um maior consumo de energia, lipídio, carboidrato, proteína, vitamina $C$ e vitamina $A(p<0,05)$. Entretanto, os hábitos alimentares foram semelhantes em ambos os grupos. Um maior percentual de crianças com sobrepeso tinha hábito, passado e/ou atual, de realizar dietas $(p<0,05)$.

\section{Conclusão}

Este estudo confirma a importância do trabalho de reeducação nutricional, tanto em crianças eutróficas quanto naquelas com sobrepeso, ressaltando a necessidade de uma alimentação mais saudável e variada nesta faixa etária, bem como a conscientização quanto ao tamanho das porções ingeridas pelas crianças com sobrepeso.

Termos de indexação: criança; estado nutricional; hábitos alimentares.

\footnotetext{
1 Artigo elaborado a partir da dissertação de J.F. NOVAES, intitulada "Fatores de risco para o sobrepeso em crianças do município de Viçosa-MG". Universidade Federal de Viçosa, 2005. Apoio: Fundação de Amparo à Pesquisa do Estado de Minas Gerais (FAPEMIG) - processo $n^{\circ}$ CDS 801/04.

2 Universidade Federal de Viçosa, Departamento de Nutrição e Saúde, Programa de Pós-Graduação em Ciência da Nutrição. Av. P.H. Rolfs, s/n., Campus Universitário, 36571-000, Viçosa, MG, Brasil. Correspondência para/Correspondence to: J.F. NOVAES.E-mail: <julianafnovaes@yahoo.com.br>.

${ }^{3}$ Universidade Federal de Viçosa, Departamento de Nutrição e Saúde. Viçosa, MG, Brasil.
} 
634 | J.F. NOVAES et al.

\section{A B S T R A C T}

\section{Objective}

To compare the food habits between well nourished and overweight children.

\section{Methods}

Case-control study with 50 well nourished children and 50 overweight children, paired by gender, age and socioeconomic conditions. They were selected from the nutritional assessment of 2074 children aging from 6 to 8 years, enrolled in public and private schools of the urban area of Viçosa, Minas Gerais State. Nutritional status was classified according to the Body Mass Index criteria of the Center for Disease Control and Prevention. A food frequency questionnaire with the foods that contribute to overweight as well as the usual food recalls regarding week and weekend days were applied. The food recalls were also used to determine intake of energy, carbohydrates, lipids, proteins, vitamin C, vitamin A, iron, calcium and fibers. A fourth questionnaire was applied in order to determine if the children had the habit of going on diets.

\section{Results}

Food intake among overweight children was excessive. They had a higher intake of energy, lipids, carbohydrates, proteins, vitamin $\mathrm{C}$ and vitamin $\mathrm{A}(\mathrm{p}<0.05)$. However, the food habits were similar in both groups. A high percentage of overweight children had the habit or have the habit of dieting $(\mathrm{p}<0.05)$.

\section{Conclusion}

This study confirms the importance of educating both well nourished and overweight children with respect to diet. They need a healthier and more varied diet, especially at this age, and the overweight children need to make smaller meals.

Indexing terms: child; nutritional status; food habits.

\section{N T R O D U ÇÃ O}

A obesidade é a desordem crônica mais comum em crianças de sociedades industrializadas. Em alguns países sua prevalência nesse grupo tem sido muito maior que a de doenças alérgicas ${ }^{1}$.

A tendência crescente da obesidade infantil é explicada pelo aumento na ingestão de alimentos ricos em energia e pela diminuição da prática de atividade física². Nos últimos 30 anos houve mudanças nos padrões alimentares da família, com aumento no consumo de fast-foods e refeições pré-preparadas ${ }^{3}$. As crianças estão aumentando o número de refeições fora de casa e os alimentos, geralmente ingeridos, apresentam maior valor energético do que os consumidos em casa ${ }^{4}$. A redução na ingestão de gordura e açúcar, em crianças, pode ser obtida por meio da mudança dos hábitos alimentares dos pais, o que pode estender-se a todos os outros membros da família ${ }^{5}$. No entanto, é importante ressaltar que a utilização de dietas restritivas como, por exemplo, uma alimentação com muito baixa ingestão de gordura, pode estar associada à deficiência de vitaminas lipossolúveis. Assim, é necessário que os pais estejam conscientes no sentido de não adotar uma alimentação reduzida em gordura sem orientação, pois esta tende a ser deficiente em energia e nutrientes importantes para as defesas imunológicas e o desenvolvimento neural na infância, bem como para o crescimento e desenvolvimento adequados da criança ${ }^{6,7}$.

Este estudo objetivou comparar os hábitos alimentares entre crianças eutróficas e com sobrepeso, matriculadas em escolas urbanas públicas e privadas do município de Viçosa, MG, no ano de 2004.

\section{MÉ TODOS}

Em 2003, após este estudo ter sido aprovado pelo Comitê de Ética em Pesquisa com Seres Humanos da Universidade Federal de Viçosa (Protocolo: 40504352236), foram pesados e medidos todos os escolares com faixa etária de 6 a 8 anos $(n=2.074)$, matriculados em todas as 
escolas urbanas públicas (19) e privadas (7) que atendiam esta faixa etária e aceitaram, espontaneamente, participar do estudo. Somente um colégio público não participou do estudo, devido à não autorização da respectiva direção escolar. Decidiu-se avaliar o total da população, ao invés de uma amostra estimada, a fim de fornecer um maior tamanho amostral aos grupos posteriormente selecionados para o estudo (sobrepeso e eutrófico), garantindo, assim, maior consistência à análise estatística e, conseqüentemente, melhor confiabilidade nos resultados.

A partir dos valores de peso e estatura aferidos em locais apropriados das respectivas escolas, calculou-se o Índice de Massa Corporal (IMC) e, de acordo com a idade e o sexo, definiu-se o estado nutricional das crianças segundo a classificação proposta pelo Centers for Disease Control and Prevention (CDC) 8 : magreza ou baixo peso (<percentil 5), eutrofia ( $\geq$ percentil 5 e $<$ percentil 85 ), risco de sobrepeso ( $\geq$ percentil 85 e $<$ percentil 95) e sobrepeso ( $\geq$ percentil 95 ). A referência antropométrica também foi baseada no $C D C^{8}$. É importante ressaltar que, segundo o $C D C^{8}$, sobrepeso é o termo preferido para se referir a crianças e adolescentes, cujo excesso de peso corporal pode resultar em riscos à saúde com conseqüências negativas. Valores de IMC superiores ao percentil 95 foram definidos como sobrepeso, e não obesidade, porque este índice não mede gordura corporal e não há consenso sobre o ponto de corte que indique obesidade em crianças ${ }^{9}$.

Toda a avaliação antropométrica foi realizada pelo mesmo profissional, para minimizar possíveis vieses na aferição de medidas. O peso foi obtido utilizando-se balança portátil, digital e eletrônica, com capacidade de 150 quilos e sensibilidade de 50 gramas. A estatura foi verificada com estadiômetro, com extensão de 2 metros, dividido em centímetros e subdividido em milímetros. A aferição dessas duas medidas baseou-se na preconização de Jelliffe ${ }^{10}$.

A partir da avaliação antropométrica realizada nas escolas iniciou-se o estudo caso-controle, no qual as crianças com sobrepeso (grupo caso) e as eutróficas (grupo controle) foram selecionadas, com pareamento na proporção de 1:1, de acordo com sexo, faixa etária, sala de aula e, conseqüentemente, escola e condição socioeconômica. Neste estudo, embora não tenham sido analisadas as variáveis socioeconômicas, considerou-se que as crianças matriculadas no mesmo tipo de escola (pública ou privada), geralmente, são pertencentes a famílias de semelhante condição socioeconômica. Assim, o critério utilizado para realizar o pareamento da condição socioeconômica foi estudar na mesma escola.

Os autores optaram por fazer o pareamento do grupo caso com o controle buscando analisar aspectos do hábito alimentar que pudessem justificar o sobrepeso, sem a interferência de variáveis que, reconhecidamente, interferem nesse hábito, tais como sexo, idade e condição socioeconômica.

Para este estudo foram incluídas na amostra as crianças com sobrepeso que apresentaram o IMC/idade igual ou superior ao percentil 96, pois o aumento da especificidade reduz a possibilidade de obter crianças falso-positivas. O critério de seleção das eutróficas ( $5 \leq$ IMC/idade <85) baseou-se na escolha aleatória de crianças com mesmo sexo e da mesma escola das com sobrepeso e, exatamente, com a mesma idade. É importante ressaltar que o tamanho amostral foi delimitado de acordo com as prevalências encontradas de sobrepeso na avaliação nutricional total das crianças do município, ocorrendo, posteriormente, o pareamento com as eutróficas.

Foram encontradas $58(2,8 \%)$ crianças com sobrepeso ( $\geq$ percentil 96 ), no município em estudo. Houve perda de 8 crianças com sobrepeso $(6,9 \%)$ e, conseqüentemente, seus pares eutróficos não foram avaliados (8). Essas perdas ocorreram pois, segundo relato materno, a criança já estava em acompanhamento nutricional com outro profissional (2) e por indisponibilidade de tempo das mães de participarem do estudo (4). Além disso, estabeleceu-se a seleção dos grupos de crianças com sobrepeso e eutróficas no fim do 
ano de 2003. No início do ano de 2004, período em que foi aplicado o questionário para a coleta de dados, as crianças foram novamente pesadas e medidas a fim de confirmar o diagnóstico nutricional. Duas crianças que apresentaram sobrepeso em 2003, na coleta de dados em 2004, quando foram reavaliadas, estavam em risco de sobrepeso, ocorrendo, assim, perda de duas com sobrepeso.

O estudo foi realizado no Laboratório de Avaliação Nutricional do Departamento de Nutrição e Saúde da Universidade Federal de Viçosa, ao qual os pais e as crianças que aceitaram, espontaneamente, participar do estudo compareciam para a coleta de dados, realizada durante o ano de 2004.

Por questões éticas, as mães cujas crianças não foram identificadas como eutróficas foram informadas sobre o estado nutricional de seu filho e encaminhadas ao serviço público de saúde, onde o atendimento nutricional foi realizado. Coletadas todas as informações necessárias para a realização do estudo, as crianças participantes receberam, individualmente, orientação nutricional específica, objetivando à melhoria do hábito alimentar, conforme os dados alimentares relatados pelas mães e o seu estado nutricional.

Os hábitos alimentares das crianças foram avaliados por um questionário de freqüência seletiva de alimentos e dois recordatórios alimentares habituais (relativos aos dias de semana e fins de semana).

Antes de aplicar o questionário de freqüência seletiva de alimentos, foi realizado um estudo-piloto com 10 mães ou responsáveis por crianças de 5 e 9 anos, que apresentavam sobrepeso e estavam matriculadas nas mesmas escolas envolvidas no estudo. Este estudo-piloto englobou a aplicação de questionário de freqüência alimentar, formulado pelos próprios autores, segundo o hábito alimentar regional, e objetivou confirmar os hábitos alimentares dessa população infantil, visando à inclusão ou exclusão de alimentos que contribuíssem para o excesso de peso infantil. Apesar de a amostra se constituir de crianças de 6 a 8 anos, o estudo-piloto alimentar foi realizado com crianças de 5 e 9 anos, devido à impossibilidade de perda da amostra, sendo importante ressaltar que os hábitos alimentares das duas faixas etárias se assemelham ${ }^{11}$.

Formulou-se, então, o questionário de freqüência seletiva dos alimentos que contribuem para o sobrepeso infantil, sendo esta analisada em cinco grupos de alimentos: cereais e massas; leite e derivados; carnes e ovos; açúcares e doces; e gorduras. As freqüências de consumo foram classificadas em não-consumo, menor que uma vez por semana, uma a três vezes por semana, quatro a cinco vezes por semana e seis a sete vezes por semana. Juntamente com o questionário de freqüência seletiva de alimentos, foi aplicado o recordatório alimentar habitual relativo aos dias de semana, sendo entrevistadas, preferencialmente, as mães. Quando essas não podiam comparecer, os inquéritos alimentares foram aplicados a outros responsáveis pelas crianças (3\% - pai, avó ou tia). Esse recordatório foi composto pelo tipo de refeição, hora, local, alimento e quantidade ingerida (em medidas caseiras). A adequação de proteínas, ferro, vitamina $A$ e vitamina $C$ foi calculada, de acordo com a necessidade média estimada (Estimated Average Requirement/EAR) $)^{12-15}$. O consumo de fibras e cálcio foi avaliado, com base nos valores da ingestão adequada (Adequate Intake/Al), pois não existem EARs para esses nutrientes ${ }^{13,16}$. A avaliação da ingestão de energia foi feita utilizando-se a necessidade energética estimada (Estimated Energy Requirement/EER), que é o consumo de energia necessário para atender o balanço energético compatível com um bom estado de saúde ${ }^{13}$. Analisou-se, também, a distribuição relativa dos macronutrientes da dieta, em relação ao valor energético total (VET) utilizando-se, como referência, os valores recomendados de AMDR (Acceptable Macronutrients Distribution Range): carboidratos, $45 \%$ a $65 \%$; proteínas, $10 \%$ a $30 \%$; e lipídios, 25\% a 35\% do VET ${ }^{13}$.

Com a finalidade de avaliar o hábito alimentar no fim de semana, foi aplicado outro recordatório alimentar habitual, relativo a esse 
período, sendo analisados os mesmos nutrientes. Os recordatórios alimentares habituais relativos aos dias de semana e ao fim de semana foram avaliados em conjunto, baseando-se na média da ingestão energética e dos nutrientes, obtida nesses dois inquéritos, sendo que, a partir dessa, foi avaliada a mediana de consumo, representando, portanto, o consumo habitual total das crianças.

Para auxiliar as mães ou os responsáveis na determinação do tamanho das porções ingeridas, foram utilizadas figuras de utensílios e porcionamento de alguns alimentos ${ }^{17}$.

Em questionário aplicado às mães, verificou-se a prática passada e/ou atual das crianças quanto à realização de algum tipo de dieta, bem como se houve orientação profissional.

O banco de dados e as análises estatísticas foram realizados utilizando-se os softwares Epi Info e Sigma-Stat. Para verificar se a distribuição dos valores das variáveis era normal, utilizou-se o teste de normalidade de Kolmogorov-Smirnov. A associação entre cada fator e o sobrepeso das crianças foi analisada por meio do teste do Qui-quadrado de McNemar, indicado para amostras pareadas. O teste de Wilcoxon foi utilizado para comparar as medianas das variáveis entre os grupos pareados, respectivamente. Considerou-se, como nível de significância estatística, a probabilidade inferior a $5 \%$.

\section{RESULTADOS}

Foi analisada a ingestão dietética relativa ao habitual nos dias de semana e nos finais de semana, o que corresponde à ingestão habitual total das crianças, pelo método do recordatório alimentar (Tabela 1). Verificou-se diferença estatisticamente significante para a ingestão de energia $(p<0,001)$, proteínas $(p<0,001)$, carboidratos $(p<0,001)$, lipídios $(p=0,001)$, vitamina $C(p=0,017)$ e vitamina $A(p=0,012)$, sendo o consumo mediano superior no grupo das com sobrepeso em relação ao das eutróficas.

A inadequação energética e de nutrientes, apresentada na Tabela 2, refere-se à ingestão que não atingiu o valor de EER e EAR para a faixa etária em questão. Quanto ao percentual de inadequação da contribuição energética dos macronutrientes, não se observou diferença estatisticamente significante entre os dois grupos (Tabela 3). É importante ressaltar que não foi encontrada nenhuma criança apresentando inadequação da ingestão de ferro, em suas respectivas refeições habituais. Para o cálcio e as fibras, não foi possível calcular o percentual de inadequação, uma vez que as EARs desses nutrientes não se encontram disponíveis. Ao comparar a ingestão dietética com as Als preconizadas para esses nutrientes, também não foi encontrada

Tabela 1. Consumo mediano de energia, proteína, vitaminas e minerais de crianças, relativo ao habitual em dias de semana e fim de semana, segundo o estado nutricional. Viçosa, MG, 2004.

\begin{tabular}{|c|c|c|c|c|c|c|c|}
\hline \multirow{3}{*}{ Energia e nutrientes } & \multicolumn{6}{|c|}{ Crianças } & \multirow{3}{*}{$p$} \\
\hline & \multicolumn{3}{|c|}{ Sobrepreso } & \multicolumn{3}{|c|}{ Eutróficas } & \\
\hline & $\mathrm{Mi}$ & (Min & - Máx) ${ }^{a}$ & $\mathrm{Mi}$ & $(\mathrm{Mi}$ & - Máx) ${ }^{a}$ & \\
\hline Energia (kcal) & 2589,4 & $(1045,4$ & $4-5869,8)$ & 2014,5 & $(981,8-$ & $3640,2)$ & $<0,001 *$ \\
\hline Proteínas (g) & 85,1 & $(42,6$ & $-245,2)$ & 73,5 & $(31,0 \quad-$ & $130,9)$ & $<0,001$ * \\
\hline Carboidrato (g) & 392,3 & $(148,9$ & $-\quad 16,0)$ & 299,2 & $(159,2-$ & $565,1)$ & $<0,001$ * \\
\hline Lipídios (g) & 78,9 & $(32,1$ & $-\quad 39,3)$ & 59,7 & $(22,7 \quad-$ & $124,7)$ & 0,001 * \\
\hline Vitamina C (mg) & 72,8 & $(3,1$ & $-225,6)$ & 52,7 & $(6,2$ & $151,0)$ & 0,017 * \\
\hline Vitamina A ( $\mu \mathrm{gRE})$ & 465,3 & $(36,8$ & $-5494,0)$ & 328,0 & $(0,0$ & $2044,1)$ & 0,012 * \\
\hline Ferro $(\mathrm{mg})$ & 14,7 & $(6,7$ & $-\quad 39,4)$ & 12,8 & $(6,5$ & $25,5)$ & 0,137 \\
\hline Cálcio (mg) & 759,4 & $(219,4$ & $-2530,8)$ & 801,0 & $(252,7-$ & $1409,5)$ & 0,302 \\
\hline Fibras alimentares (g) & 16,5 & $(3,9$ & $-\quad 50,2)$ & 14,6 & $(1,1)$ & $55,2)$ & 0,582 \\
\hline
\end{tabular}

a Mediana (Valor mínimo - Valor Máximo); o valor de $p$ foi originado do teste de Wilcoxon; * $p<0,05$. 
diferença estatística significante entre os dois grupos ( $p=0,71$ e $p=1,00$; respectivamente - dados não apresentados em tabela). No entanto, vale ressaltar que, embora a impossibilidade de calcular o percentual de inadequação para os nutrientes cuja EAR não está disponível, 86 e $84 \%$ das crianças com sobrepeso e eutróficas apresentaram ingestão de fibras abaixo do valor da ingestão adequada, enquanto para o cálcio esses valores foram 56 e $50 \%$, respectivamente (dados não apresentados em tabela).

Quanto à distribuição relativa dos macronutrientes da alimentação, em relação ao valor energético total, tanto as crianças com sobrepeso quanto as eutróficas apresentaram valores dentro da faixa indicada na Acceptable Macronutrients Distribution Range (AMDR) ${ }^{13}$ : carboidratos, 45\% - 65\%; lipídios, 25\% a 35\%; e proteínas, 10\% a $30 \%$ (Tabela 3). Esses valores mostram que, apesar do consumo mediano superior dos macronutrientes pelas crianças com sobrepeso, em relação ao VET, as quantidades apresentaram-se dentro das faixas preconizadas.

A Tabela 4 apresenta o percentual da freqüência de consumo de alimentos que contribuem para o sobrepeso em crianças, obtido pelo questionário de freqüência seletiva, sendo cada grupo alimentar representado pelo alimento mais consumido à freqüência de seis a sete vezes por semana. Assim, os alimentos mais destacados entre as crianças com sobrepeso e eutróficas foram semelhantes: pão branco (cereais e massas); queijo (leite e derivados); carnes e ovos fritos (carnes e ovos); bala, chicletes e pirulito (açúcares e doces); e margarina (gorduras). Observou-se maior percentual de crianças com sobrepeso, que consumiam queijo na freqüência de seis a sete vezes por semana, em relação às eutróficas

Tabela 2. Prevalência de inadequação de energia, proteína, vitaminas e minerais entre as crianças, segundo o estado nutricional. Viçosa, MG, 2004.

\begin{tabular}{|c|c|c|c|c|}
\hline \multirow{3}{*}{ Energia e nutrientes } & \multirow{3}{*}{$\begin{array}{l}\text { Parâmetro de } \\
\text { comparação }\end{array}$} & \multicolumn{2}{|c|}{ Crianças } & \multirow{3}{*}{$p$} \\
\hline & & Sobrepeso & Eutróficas & \\
\hline & & Inadequação (\%) & Inadequação (\%) & \\
\hline Energia $(\mathrm{kcal})^{\mathbf{a}}$ & ** & 24,0 & 22,0 & 1,000 \\
\hline Proteínas $(\mathrm{g})^{\mathbf{b}}$ & $* * *$ & 0,0 & 0,0 & - \\
\hline Vitamina $C(m g)^{\mathbf{b}}$ & 22,0 & 8,0 & 16,0 & 0,289 \\
\hline Vitamina A ( $\mu g R E)^{\mathbf{b}}$ & 275,0 & 28,0 & 42,0 & 0,497 \\
\hline Ferro $(m g)^{\mathbf{b}}$ & 4,1 & 0,0 & 0,0 & - \\
\hline Cálcio $(\mathrm{mg})^{\mathbf{c}}$ & 800,0 & - & - & - \\
\hline Fibras alimentares $(\mathrm{g})^{\mathbf{c}}$ & 25,0 & - & - & - \\
\hline
\end{tabular}

a EER: necessidade energética estimada; 'bEAR: necessidade média estimada; 'Al: ingestão adequada; ** recomendação preconizada individualmente (EER) de acordo com o sexo, faixa etária e o nível de atividade física; *** recomendação preconizada individualmente (EAR): gramas de proteínas ingeridas/kg de peso; o valor de $p$ foi originado do teste do Qui-quadrado de McNemar.

Tabela 3. Percentual de consumo de macronutrientes em relação ao VET*, segundo o estado nutricional das crianças. Viçosa, MG, 2004

\begin{tabular}{|c|c|c|c|c|}
\hline \multirow{3}{*}{ Macronutrientes } & \multicolumn{4}{|c|}{ Percentual em relação ao VET das crianças } \\
\hline & \multicolumn{2}{|c|}{ Dias de semana } & \multicolumn{2}{|c|}{ Fim de semana } \\
\hline & Sobrepeso & Eutróficas & Sobrepeso & Eutróficas \\
\hline Carboidrato & 61,4 & 60,4 & 59,0 & 61,0 \\
\hline Lipídio & 25,2 & 26,4 & 27,1 & 26,0 \\
\hline Proteína & 13,4 & 13,2 & 13,9 & 13,0 \\
\hline
\end{tabular}

* VET: valor energético total. 
Tabela 4. Consumo de alimentos que contribuem para o sobrepeso pelas crianças, na freqüência de seis a sete vezes por semana, segundo o estado nutricional Viçosa, MG, 2004.

\begin{tabular}{|c|c|c|c|}
\hline \multirow{2}{*}{ Grupo alimentar } & \multicolumn{2}{|c|}{ Crianças } & \multirow{2}{*}{$p$} \\
\hline & Sobrepeso (\%) & Eutróficas (\%) & \\
\hline Cereais e massas (pão branco) & 70,8 & 58,3 & 0,28 \\
\hline Leite e derivados (queijo) ${ }^{\mathrm{a}}$ & 22,9 & 6,0 & $0,02 *$ \\
\hline Carnes/ovos (ambos fritos) ${ }^{\mathbf{b}}$ & $39,6 / 60,4$ & $41,7 / 70,8$ & $1,00 / 0,50$ \\
\hline Açúcares e doces (bala, chicletes e/ou pirulito) & 33,3 & 25,0 & 0,50 \\
\hline Gorduras (margarina) & 50,0 & 62,5 & 0,28 \\
\hline
\end{tabular}

a muzarela ou minas; bambos os consumidos na freqüência de uma a três vezes por semana; o valor de $p$ foi originado do teste do Qui-quadrado de McNemar; ${ }^{*} p<0,05$.

(22,9\% vs $6,0 \% ; p=0,02)$, sendo os tipos mais citados o minas e o muzarela. No entanto, para os demais alimentos selecionados como contribuintes para o sobrepeso infantil, não foi encontrada diferença na freqüência de consumo entre o grupo de crianças eutróficas e aquelas com sobrepeso.

Neste estudo, observou-se diferença, estatisticamente significante quanto à prática de já ter realizado ou estar realizando algum tipo de dieta, em que $22,0 \%$ das crianças com sobrepeso já apresentaram esse hábito, não sendo encontrada tal situação em nenhuma eutrófica $(p=0,002)$. Verificou-se que $100 \%$ das crianças com sobrepeso, que já realizaram dietas, foram orientadas por profissionais de saúde, sendo $63,6 \%$ por nutricionista e $36,4 \%$ por médico (dados não apresentados em tabela).

\section{DIS CUSS Ã O}

Em relação aos dados do recordatório alimentar habitual, os resultados comprovam a superior ingestão de alimentos pelas crianças com sobrepeso, ressaltando um maior consumo de energia, carboidrato, lipídio, proteína, vitamina A e vitamina $C$ em relação às eutróficas. É importante ressaltar que os hábitos alimentares foram semelhantes entre as crianças eutróficas e aquelas com sobrepeso, ou seja, grande parte dos alimentos consumidos era similar entre os dois grupos; entretanto, estas últimas apresentaram uma ingestão significativamente superior em relação às eutróficas.
Quanto ao consumo excessivo de nutrientes, resultados semelhantes foram encontrados por McGloin et al. ${ }^{18}$, que constataram que as crianças obesas consumiam maior quantidade de gordura que as eutróficas. Hui et al. ${ }^{19}$ observaram associação significante entre a ingestão energética, calculada por recordatório alimentar de três dias, e o sobrepeso das crianças aos 6 e 7 anos.

Fatores de risco para doenças cardiovasculares iniciam na infância e estão associados à acelerada aterosclerose. Hábitos alimentares inadequados podem ser observados na infância, e incluem a ingestão excessiva de energia, gordura saturada e colesterol, levando à obesidade. Tal comportamento indica a necessidade de programas preventivos, não somente para indivíduos obesos, mas, também, para crianças em geral ${ }^{20}$.

Observou-se maior consumo de vitaminas A e $C$ em crianças com sobrepeso. Com relação à vitamina $A$, esse resultado pode ser explicado pelo excessivo consumo de alimentos-fonte dessa vitamina, que normalmente são de origem animal e se constituem de elevado teor de lipídios, sendo fontes de vitamina A pré-formada, que é lipossolúvel, como fígado, manteiga, leite integral, gema de ovo, creme de leite, queijos etc ${ }^{21}$. Tal fato pode ser confirmado pelos maiores valores medianos de lipídios em geral ingeridos pelas crianças com sobrepeso, em comparação às eutróficas. Entretanto, não foram observadas diferenças significantes quanto à ingestão dos alimentos-fonte de carotenóides, precursores da vitamina $A$, entre os dois grupos de crianças $(p=0,526)$. Quanto à vitamina $C$, apesar da 
superior ingestão pelo grupo das crianças com sobrepeso, não foram encontradas diferenças significantes quanto ao consumo dos alimentos-fonte dessa vitamina entre os dois grupos. Uma possível explicação para a maior ingestão mediana de vitamina $C$ pelo grupo das crianças com sobrepeso, pode ser o maior consumo de sucos, em termos de quantidade, pelas crianças com sobrepeso, principalmente no horário do almoço $(p=0,011)$. Além disso, é importante ressaltar o maior consumo de sucos industrializados, pelas crianças eutróficas e com sobrepeso, em relação à forma natural, sendo a quantidade ingerida superior nestas últimas $(p=0,019)$. Segundo Pereira et al. ${ }^{22}$, grande parte dos sucos industrializados apresenta adição de vitamina $\mathrm{C}$ em sua composição, podendo, assim, favorecer a maior ingestão dessa vitamina no grupo das crianças com sobrepeso, em virtude da maior quantidade consumida desses produtos.

Não foi encontrada diferença estatisticamente significante quanto à inadequação de energia e de nutrientes entre as crianças. Além disso, surpreendentemente, nenhuma criança com sobrepeso ou eutrófica apresentou déficit na ingestão de ferro. Entretanto, considerando a carne como uma excelente fonte de ferro, esperava-se encontrar deficiência desse mineral na alimentação de algumas crianças, uma vez que, na análise do recordatório habitual relativo aos dias de semana e fim-de-semana, observou-se que apenas $78 \%$ e $60 \%$ das crianças com sobrepeso e eutróficas consumiam carne todos os dias, respectivamente. No entanto, a ingestão mediana de ferro das crianças apresentava-se acima do valor de EAR, que preconiza a necessidade média e não meta de ingestão.

Sabe-se que uma alimentação equilibrada é indispensável ao crescimento e desenvolvimento adequado. É importante ressaltar que o aumento do consumo energético a partir de sacarose e gorduras, não está associado, necessariamente, à melhoria qualitativa da dieta em relação a micronutrientes, que podem estar deficitários, mesmo em uma dieta hiperenergética. Muitas vezes, a ingestão de nutrientes essenciais como ferro, zinco e cálcio está abaixo do recomendado para crianças e adolescentes ${ }^{23}$. Segundo Strauss ${ }^{24}$, a prática profissional diária e a literatura científica têm demonstrado o déficit na ingestão de vitaminas, por parte das crianças, em particular as portadoras de obesidade.

Rogers et al. ${ }^{25}$ verificaram que altas ingestões de gordura estavam associadas à alimentação deficiente em ferro, além da existência de baixos níveis séricos de ferritina. Resultados semelhantes foram encontrados por Pinhas-Hamiel et al. ${ }^{26}$, que constataram anemia ferropriva em 6,7\%; 35,0\% e $58,3 \%$ de crianças e adolescentes eutróficos, com sobrepeso e obesos, respectivamente. Segundo os autores, a deficiência de ferro é comum em crianças com obesidade, sendo que, devido ao seu potencial efeito danoso, essas crianças devem ser avaliadas e tratadas, rotineiramente, quando necessário.

De acordo com a análise da freqüência seletiva de alimentos contribuintes para o sobrepeso infantil, os resultados confirmam o semelhante hábito alimentar entre as crianças com sobrepeso e eutróficas, sendo que os alimentos mais consumidos, em cada grupo alimentar, são similares em ambos os grupos. Para todos os alimentos, com exceção do queijo, não foi encontrada diferença na freqüência do consumo entre os grupos. Resultados semelhantes foram encontrados em outros estudos, sendo observado que, para todos os itens do questionário de freqüência alimentar avaliados, não houve diferença entre o consumo de crianças obesas e aquele das eutróficas ${ }^{27-29}$. No entanto, vale ressaltar a dificuldade de avaliar, fidedignamente, o consumo dietético, pois todos os instrumentos apresentam limitações ${ }^{12}$. Quanto ao questionário de freqüência de consumo alimentar, as limitações do método incluem dependência de memória da freqüência da ingestão de alimentos pelo entrevistado, bem como o tempo gasto em sua realização $0^{30}$.

Foram observadas a prática atual e passada de dieta entre as crianças com sobrepeso, porém todas receberam orientação de um profissional especializado, sendo esse um resultado favorável. Sabe-se que, geralmente, crianças com sobrepeso desejam realizar dietas a fim de perder peso. No entanto, muitas o fazem por conta própria ou por 
informação de familiares, revistas, amigos e outros, ou seja, sem orientação profissional. O aconselhamento para a realização de dieta na infância deve ser realizado com muita cautela, em razão da fase de intenso crescimento. A utilização de dietas restritivas é contra-indicada na infância, pois podem levar à perda de tecido muscular e à diminuição da velocidade de crescimento e desenvolvimento ${ }^{31}$. A reeducação alimentar é a melhor forma de tratamento e deve ser mantida por toda a vida ${ }^{23}$. Assim, também é importante ressaltar o tipo de conduta preconizada para o estímulo à reeducação alimentar da criança, uma vez que, geralmente, ela não altera o seu estado nutricional após as orientações nutricionais, que podem basear-se na restrição acentuada de energia e proibição de alimentos preferidos. Muitas vezes, as crianças não possuem maturidade suficiente para entender essa rígida reeducação alimentar, estipulada pelo profissional de saúde, para sua perda de peso e promoção da saúde. Segundo Valverde \& Patin $^{32}$, em acompanhamento nutricional infantil, é importante utilizar técnicas e estratégias facilitadoras do aprendizado e da mudança de comportamento alimentar, evitando-se os riscos de fornecer orientações padronizadas e, principalmente, evitando tratar o paciente como um adulto em miniatura. O desenvolvimento de habilidades de relacionamento e o estabelecimento de forte vínculo entre a criança e o profissional de sáude, assim como o envolvimento da família no processo, são fundamentais para o êxito do tratamento.

Uma limitação deste estudo são os vieses de resposta e o de memória existentes na aplicação dos inquéritos dietéticos. Para minimizar o erro do relato materno sobre o consumo alimentar da criança, foi enfatizada, no início do atendimento nutricional, a importância da veracidade das informações relatadas por ela, permitindo ao profissional orientá-la em relação ao hábito alimentar do seu filho.

Neste estudo, identificou-se que a quantidade de alimentos ingeridos pelas crianças com sobrepeso é elevada, evidenciando um maior consumo de energia e nutrientes em relação às eutróficas, tais como lipídio, carboidrato, proteína, vitamina $C$ e vitamina A. Além disso, tanto as crianças eutróficas quanto aquelas com sobrepeso apresentaram hábitos alimentares semelhantes, sendo os alimentos mais consumidos de cada grupo alimentar similares em ambos os grupos. Este resultado confirma a relevância da reeducação nutricional, contemplando tanto as crianças eutróficas quanto as com sobrepeso, ressaltando a importância de uma alimentação saudável e variada, além da importância de trabalhar o tamanho das porções ingeridas pelas crianças com sobrepeso.

\section{A GRADECIMENTOS}

À Coordenação de Aperfeiçoamento de Pessoal de Nível Superior (Capes) pela concessão da bolsa de mestrado, à Fundação de Amparo à Pesquisa do Estado de Minas Gerais (Fapemig) pelo financiamento do projeto, ao Departamento de Nutrição e Saúde da Universidade Federal de Viçosa pelo apoio, às crianças e aos pais pela participação no estudo.

\section{COLABORADORES}

J. F. NOVAES, participou da coleta de dados, escrita do manuscrito e análise estatística. S.E. PRIORE e S.C.C. FRANCESCHINI participaram na orientação do estudo, redação e análise estatística.

\section{REFERÊ NCIAS}

1. Kiess W, Reich A, Muller G, Meyer K, Galler A, Bennek J, et al. Clinical aspects of obesity in childhood and adolescence: diagnosis, treatment and prevention. Int J Obes. 2001; 25(Suppl 1): S75-S79

2. Marins VMR, Almeida RMVR, Pereira MBA. Factors associated with overweight and central body fat in the city of Rio de Janeiro: results of a two-stage random sampling survey. Public Health. 2001: 115(3):1-7.

3. Dietz $\mathrm{WH}$. The obesity epidemic in young children. BMJ. 2001; 322(7282):313-4.

4. Schwartz MB, Puhl R. Childhood obesity: a societal problem to solve. Obes Rev. 2003; 4:57-71.

5. Epstein LH, Gordy CC, Raynor HA, Beddome M, Kilanowski CK, Paluch R. Increasing fruit and vegetable intake and decreasing fat and sugar 
intake in families at risk for childhood obesity. Obes Res. 2001; 9(3):171-8.

6. Sigman-Grant M, Zimmerman S, Kris-Etherton PM. Dietary approaches for reducing fat intake of preschool-age children. Pediatrics. 1993; 91(5): 955-60.

7. Butte NF. Fat intake of children in relation to energy requirements. Am J Clin Nutr. 2000; 72(5): 1246S-52S.

8. Centers for Disease Control and Prevention. 2000 CDC Growth Charts for the United States: methods and development. Vital Health Statistics. 2000; 11(246):189.

9. World Health Organization. Obesity: preventing and managing the global epidemic. Geneva; 1998 Report of a WHO Consultation on Obesity.

10. Jelliffe DB. Evaluación del estado de nutrición de la comunidad. Ginebra: OMS; 1968. OMS Série de monografías, 53.

11. Accioly E, Saunders C, Lacerda EMA. Nutrição em obstetrícia e pediatria. Rio de Janeiro: Cultura Médica; 2003.

12. National Research Council. Dietary references intakes: applications in dietary assessment. Washington (DC): National Academy Press; 2001.

13. National Research Council. Dietary reference intakes for energy, carbohydrate, fiber, fat, fatty acids, cholesterol, protein, and amino acids (macronutrients). Washington (DC): National Academy Press; 2002.

14. National Research Council. Dietary reference intakes for vitamin A, vitamin $\mathrm{K}$, arsenic, boron, chromium, copper, iodine, iron, manganese, molybdenum, nickel, silicon, vanadium, and zinc. Washington (DC): National Academy Press; 2002.

15. National Research Council. Dietary reference intakes for vitamin C, vitamin E, selenium, and carotenoids. Washington (DC): National Academy Press; 2002.

16. National Research Council. Dietary reference intakes for calcium, phosphorus, magnesium, vitamin D, and fluoride. Washington (DC): National Academy Press; 1999.

17. Zabotto, CB. Registro fotográfico para inquéritos dietéticos: utensílios e porções. Campinas: Unicamp; 1996.

18. McGloin AF, Livingstone MB, Greene LC, Webb SE, Gibson JM, Jebb AS, et al. Energy and fat intake in obese and lean children at varying risk of obesity. Int J Obes. 2002; 26(2):200-7.

19. Hui LL, Nelson EAS, Yu LM, Li AM, Fok TF. Risk factors for childhood overweight in 6- to 7-y-old Hong Kong children. Int J Obes. 2003; 27(11):1411-8.
20. Berenson GS, Srinivasan SR, Nicklas TA. Atherosclerosis: a nutritional disease of childhood. Am J Cardiol. 1998; 82(10B):22T-29T.

21. Philippi ST. Tabela de composição de alimentos: suporte para decisão nutricional. Brasília: Anvisa; 2001.

22. Pereira CAS, Rezende FAC, Tuccori LP, Souza CJ. Informações nutricionais de produtos industrializados. Viçosa: UFV; 2003.

23. Sigulem DM, Taddei JAAC, Escrivão MAMS, Devincenzi MU. Obesidade na infância e na adolescência. Compacta Nutr. 2001; 2:5-16.

24. Strauss RS. Comparison of serum concentrations of alpha-tocopherol and beta-carotene in a crosssectional sample of obese and non-obese children (NHANES III). National Health and Nutrition Examination Survey. J Pediatr. 1999; 134(2):160-5.

25. Rogers IS, Emmett PM, Alspac Study Team. Fat content of the diet among preschool children in southwest Britain: II relationship with growth blood lipids and iron status. Pediatrics. 2001; 108(3):1-9.

26. Pinhas-Hamiel O, Newfield RS, Koren I, Agmon A, Lilos P, Phillip M. Greater prevalence of iron deficiency in overweight and obese children and adolescents. Int J Obes. 2003; 27(3):416-8.

27. Klesges RC, Hanson CL, Eck LH, Durff AC. Accuracy of self-reports of food intake in obese and normalweight individuals: effects of parental obesity on reports of children's dietary intake. Am J Clin Nutr. 1988; 48(5):1252-6.

28. Maffeis C, Provera S, Filippi L, Sidoti G, Schena S, Pinelli $L$, et al. Distribution of food intake as a risk factor for childhood obesity. Int J Obes. 2000; 24(1):75-80.

29. Danielzik S, Czerwinski-Mast M, Langnase K, Dilba B, Muller MJ. Parental overweight, socioeconomic status and high birth weight are the major determinants of overweight and obesity in 5-7 $y$-old children: baseline data of the Kiel Obesity Prevention Study (KOPS). Int J Obes. 2004; 28(11):1494-502.

30. Duarte ACG, Castellani FR. Semiologia nutricional. Rio de Janeiro: Axcel Books; 2002.

31. Escrivão MAMS, Oliveira FLC, Taddei JAAC, Lopez FA. Obesidade exógena na infância e na adolescência. J Pediatr. 2000; 76(Supl.3): S305-\$310.

32. Valverde MA, Patin RV. Aconselhamento dietético e mudança de comportamento. In: Fisberg M. Atualização em obesidade na infância e adolescência. São Paulo: Atheneu; 2004.

Recebido em: 5/6/2006 Versão final reapresentada em: 29/6/2007 Aprovado em: 21/8/2007 